\title{
Comparative Analysis of Rigid PVC Foam Reinforced with Class C and Class F Fly Ash
}

\author{
Parisa Khoshnoud, Subhashini Gunashekar, Murtatha M. Jamel, Nidal Abu-Zahra* \\ Materials Science and Engineering Department, University of Wisconsin-Milwaukee, Milwaukee, USA \\ Email: "nidal@uwm.edu
}

Received 28 August 2014; revised 19 October 2014; accepted 30 October 2014

Academic Editor: Jiann-Yang (Jim) Hwang, Michigan Technological University, USA

Copyright (C) 2014 by authors and Scientific Research Publishing Inc.

This work is licensed under the Creative Commons Attribution International License (CC BY).

http://creativecommons.org/licenses/by/4.0/

(c) (i) 0pen Access

\section{Abstract}

Fly ash particles are usually spherical and based on their chemical composition; they are categorized into two classes: $\mathrm{C}$ and $\mathrm{F}$. This study compares the microstructural, mechanical and thermal properties of extruded rigid PVC foam composites reinforced with class $C$ and class $F$ fly ash. The mechanical properties: such as tensile and flexural strength of composites containing class $C$ fly ash were superior to the composites containing class $\mathrm{F}$ fly ash particles. Composites containing 6 phr class C fly ash showed a $24 \%$ improvement in the tensile strength in comparison to a mere $0.5 \%$ increase in composites reinforced with class F fly ash. Similarly, the addition of $6 \mathrm{phr}$ of class F fly ash to the PVC foam matrix resulted in a $5.74 \%$ decrease in the flexural strength, while incorporating the same amount of class $\mathrm{C}$ fly ash led to a $95 \%$ increase in flexural strength. The impact strength of the composites decreased as the amount of either type of fly ash increased in the composites indicating that fly ash particles improve the rigidity of the PVC foam composites. No significant changes were observed in the thermal properties of the composites containing either type of fly ash particles. However, the thermo-mechanical properties measured by DMA indicated a steep increase in the viscoelastic properties of composites reinforced with class $C$ flyash. The microstructural properties studied by Scanning Electron Microscopy (SEM) confirmed that fly ash particles were mechanically interlocked in the PVC matrix with good interfacial interaction with the matrix. However, particle agglomeration and debonding was observed in composites reinforced with higher amounts of fly ash.

\section{Keywords}

Rigid PVC Foam, Class C Fly Ash, Class F Fly Ash, Thermo-Mechanical Properties, Morphology

\footnotetext{
${ }^{*}$ Corresponding author.
}

How to cite this paper: Khoshnoud, P., Gunashekar, S., Jamel, M.M. and Abu-Zahra, N. (2014) Comparative Analysis of Rigid PVC Foam Reinforced with Class C and Class F Fly Ash. Journal of Minerals and Materials Characterization and Engineering, 2, 554-565. http://dx.doi.org/10.4236/jmmce.2014.26057 


\section{Introduction}

Fly ash (FA) is widely studied as reinforcing filler in metal, polymer, and cement matrices due to its unique properties; such as low density, low cost, and smooth spherical surface [1]. Approximately, 70 million tons of FA is produced annually in the United States as a byproduct of coal combustion operations, and most of it is currently disposed in landfills [2]. According to ASTM C618, fly ash can be classified based on its chemical composition into two different classes, Class $\mathrm{C}$ and Class $\mathrm{F}$. Fly ash mainly contains quartz $\left(\mathrm{SiO}_{2}\right)$, mullite $\left(3 \mathrm{Al}_{2} \mathrm{O}_{3} \cdot 2 \mathrm{SiO}_{2}\right)$, hematite $\left(\mathrm{Fe}_{2} \mathrm{O}_{3}\right)$, magnetite $\left(\mathrm{Fe}_{3} \mathrm{O}_{4}\right)$, lime $(\mathrm{CaO})$, and gypsum $\left(\mathrm{CaSO}_{4} \cdot 2 \mathrm{H}_{2} \mathrm{O}\right)$, however the proportion of each compound differs in each class of FA [3] [4]. Class F fly ash (FA-F) is produced as a byproduct of burning anthracite or bituminous coal and contains less than $20 \%$ lime. On the other hand, Class C fly ash (FA-C) is a byproduct of burning sub-bituminous coal and lignite and contains more than $20 \%$ lime. FA-C usually has cementitious properties as well as pozzolanic properties, meaning that it reacts with excess lime generated in the hydration of portland cement, while FA-F exhibits less cementitious properties when mixed with water alone [5].

Polymer composites are widely used due to their enhanced properties such as: strength to weight ratios and ease of fabrication [6] [7]. The effect of FA on different properties of polymer composites has been studied by a number of researchers. Qiao et al. [8] prepared Polyurea/FA composites; they showed that the dynamic mechanical properties were enhanced in the presence of FA particles. Anandhan et al. [9] studied the mechanical and thermal properties of extruded ethylene-octene random copolymer/FA composites; they reported $50 \%$ increase in tensile strength in a sample with $20 \%$ FA loading, while there was no significant change in thermal properties. Deepthi et al. [10] studied High Density Poly Ethylene (HDPE)/cenosphere FA composites using maleate ester modified HPDE; they reported improvement in mechanical and thermal properties and decrease in crystallinity. Jute-epoxy sandwiches reinforced with FA to make functionally gradient (FG) composites were prepared by Doddamani et al. [11]; they derived a correlation between FA content and their mechanical properties using a Taguchi design of experiments.

Nath et al. [12] prepared isotactic semicrystalline polypropylene/FA composites using injection molding. The composites contained $20 \%, 45 \%$ and $60 \%$ FA by weight. They reported enhancement in tensile modulus of all composites independent of the testing temperatures. Wide angle XRD (WAXRD) and DSC observations indicated that FA particles act as nucleation sites for the crystalline phase and the amount of crystallinity increased up to $11 \%$ with increasing FA. In a similar work, Nath et al. [13] [14] studied the kinetics of non-isothermal crystallization of the prepared isotactic polypropylene/FA composites; adding FA to neat PP caused partial trans-crystallization of $\alpha$ crystalline phase into $\beta$, therefore the presence of FA has led to a change in crystallinity. In addition, Nath et al. [15] [16] studied biodegradable composites of Poly Vinyl Alcohol (PVA)/FA ranging between 5 and $25 \mathrm{Wt} \%$ concentration. Tensile strength and tensile modulus increased proportionally to 193\% and $212 \%$, respectively, by the addition of $20 \%$ fly ash to the polymer. Dynamic mechanical analysis also showed an improvement in both storage and loss modulus, and a shift in $\tan \delta$ peaks towards higher temperatures.

Vijaykumar et al. [17] prepared FA-epoxy core sandwiched composites with three different proportions of epoxy and FA. Their studies on tensile and compressive strengths indicated that the composite with $60 \%$ FA had the best properties. Guhanathan et al. [18] studied the mechanical, thermal, and morphological properties of polyester/surface treated FA composites. An improvement in tensile, flexural, and impact properties of composites in the presence of FA was reported. Bishoyee et al. [19] prepared FA filled polyester-glass fiber composites and studied their erosion properties using a grey-based Taguchi approach.

However, very few researchers have studied polymer foams reinforced with FA particles. Usta, [20] investigated the flame retardancy behavior of rigid polyurethane (PU) foams containing FA using a cone calorimeter. It was reported that the incorporation of FA particles in PU foam dramatically increased the fire resistance and thermal stability of the composite foams. Choew et al. [21] reported the usage of PU foam/FA blends as a commercial product to encapsulate heavy metals. It was observed that PU foam-FA blends were waterproof, with good resistance to heat and light. The blends contained a maximum of $18 \%$ FA in their composition. Gupta et al. [22] focused on the effect of cenosphere FA radius ratio on compressive properties of syntactic foams. The results showed that compressive strength and modulus depend on the internal radius of the particles and they are higher in those specimens filled with smaller internal radius cenospheres.

Rigid Polyvinyl Chloride (PVC) foam composites are one of the most common materials used in building in- 
dustry in the form of profiles, sheets, and pipes due to their low cost, low density, low thermal conductivity, improved acoustic damping properties, and good fire retardancy [23]-[26]. PVC/FA composites are hence very attractive for several commercial applications; however, very little information is available on the effect of FA on PVC foams. This study is an attempt to understand the effect of the chemical composition of FA on the thermal, mechanical, and microstructural properties of rigid PVC foams. Two different types of FA, namely FA-C and FA-F, were added separately to the PVC foam compound at low (6 phr) and high (40 phr) loadings to compare the effect of these particles on the properties of the composites.

\section{Experimental}

\subsection{Materials}

Rigid PVC resin was purchased from Shintech, USA; it had an inherent viscosity of 0.74 (ASTM D1243); bulk density of $36.3 \mathrm{lb} / \mathrm{ft}^{3}$ (ASTM D 1895), maximum volatiles of $0.12 \%$ (ASTM D3030). A commercially available thermal stabilizer Thermolite T-137 and processing aids Plastistrength were provided by Arkema, USA; lubricants LOXIOL provided by Oleochemicals, USA; paraffin wax provided by Ferro Corp., USA; Calcium Stearate produced by Norac Corp., USA, chemical blowing agents azodicarbonamide (ADC) produced by Season Corp. and Sodium Hydrogen Carbonate (FICEL SBH) produced by Hughes Polymer Additives Corp., USA were also used in this investigation. FA-F and FA-C were collected from WE Energies power plant in Oak Creek, Wisconsin, USA.

\subsection{Preparation of PVC/Fly Ash Foam Composites}

PVC foam compound was prepared using a high shear mixer (Gunther Pepenmeier, Machinen-u. Detmoid, Type: TSHK). The stabilizer was added at $52^{\circ} \mathrm{C}$, FA and processing aids were added to the PVC resin at $52^{\circ} \mathrm{C}$ and $58^{\circ} \mathrm{C}$; respectively. Finally, the lubricants and the blowing agents were added at $66^{\circ} \mathrm{C}$. PVC foam compounds containing, 0, 6, and 40 phr FA were extruded by using a 1 inch, 20:1 (L/D) single screw extruder (Themoplas New England Wire Machinery Co. Inc.) at a screw speed of $60 \mathrm{rpm}$. The extrusion temperature profile used for mixing was in the range of $158^{\circ} \mathrm{C}$ to $175^{\circ} \mathrm{C}$. The composite formulations and sample codes based on FA content and type ( $\mathrm{C}$ and $\mathrm{F}$ ) are listed in Table 1. In the coding system of the samples, FA-F and FA-C represent the samples containing FA-F and FA-C; respectively. For example, FA-C40 is a sample reinforced with $40 \mathrm{phr}$ FA-C.

\subsection{Physical Properties}

The apparent density of the foam composites was calculated by determining the theoretical density $\left(\rho_{t h}\right)$ of PVC foam composites using the rule of mixtures. The experimental density $\left(\rho_{\text {exp }}\right)$ was calculated by weighting and measuring the volume of the extruded samples.

\subsection{Mechanical Properties}

Tensile properties were determined using an Instron 3365 universal testing machine on rectangular specimens measuring $12 " \times 1 " \times 0.265 "$ at a crosshead speed of $0.5 \mathrm{in} / \mathrm{min}$. Flexural properties were determined using Instron 3365 with a three-point bending test set-up on rectangular specimens measuring 8 " $\times 1 " \times 0.265$ " at a crosshead speed of $0.5 \mathrm{in} / \mathrm{min}$. The span length was kept at 4 inches. The flexural stress and strains were calculated using:

Table 1. PVC foam composites formulation.

\begin{tabular}{ccccc}
\hline Raw Materials (phr) & FA-F6 & FA-F40 & FA-C6 & 100 \\
PVC Resin & 100 & 100 & 0 & 00 \\
FA-F & 6 & 40 & 6 & 0 \\
FA-C & 0 & 0 & 40 \\
\hline
\end{tabular}




$$
\begin{gathered}
\sigma_{f}=\frac{3 P L}{2 b d^{2}} \\
\varepsilon_{f}=\frac{6 D d}{L^{2}}
\end{gathered}
$$

where, $\sigma_{f}$ and $\varepsilon_{f}$ are the flexural stress and strain at the midpoint; respectively, and P, L, b, d, D are the load, span length, specimen width, specimen thickness and midpoint deflection; respectively. The flexural strength was determined using the maximum stress value recorded before sample fracture and flexural modulus was determined by the slope of the initial linear region of the stress-strain curve.

Charpy impact properties were determined using Tinus Olsen impact testing machine (model IT 504) according to ASTM D 6110. The hardness was determined with a Shore-D Durometer.

\subsection{Thermal Characterization}

Thermal properties of the foam composites were analyzed using TA Instrument SDT 2960 thermo gravimetric analyzer (TGA) in the temperature range of $25^{\circ} \mathrm{C}$ to $800^{\circ} \mathrm{C}$ at a heating rate of $10^{\circ} \mathrm{C} / \mathrm{min}$ in an inert argon atmosphere. In addition, Differential Scanning Calorimetry (DSC) measurements were carried out using TA Q2000 analyzer (TA Instruments, US). Foam composite samples weighing 5 to $10 \mathrm{mg}$ were heated in standard aluminum pans in the temperature range of $25^{\circ} \mathrm{C}$ to $260^{\circ} \mathrm{C}$ at a heating rate of $10^{\circ} \mathrm{C} / \mathrm{min}$.

Dynamic Mechanical Analysis (DMA) was performed using a TA Instrument Q800 to evaluate the viscoelastic properties (storage modulus, loss modulus, and $\tan \delta$ ) of the composites in a solid state. The three-point bending mode was used at a test temperature range of $25^{\circ} \mathrm{C}$ to $120^{\circ} \mathrm{C}$ at a constant heating rate of $3^{\circ} \mathrm{C} / \mathrm{min}$ and the frequency of dynamic force of $1 \mathrm{~Hz}$.

\subsection{X-Ray Diffraction Analysis (XRD)}

Elemental and chemical analysis of the fly ash particles were determined using an X-ray diffractometer (Bruker D8 Discovery) with a $\mathrm{CuK}_{\alpha}$ radiation $(\lambda=1.54056 \AA)$ source. The samples were scanned at the rate of 1.25 $2 \theta /$ min with a step size of $0.032 \theta$ from 10 to $70(2 \theta)$.

\subsection{Scanning Electron Microscopy and Energy Dispersive X-Ray Analysis (SEM/EDX)}

Topcon SM-300 SEM was used for imaging and microstructural analysis. The specimens were fractured in liquid nitrogen and coated using a sputter coater to minimize the charging effect and to improve the conductivity of the samples prior to analysis. SEM/EDX was also used to confirm the chemical composition of Fly ash particles.

\section{Results and Discussion}

\subsection{Fly ash Characterization}

The density of FA-F and FA-C particles was measured to be 2.4 and $2.5 \mathrm{~g} / \mathrm{cm}^{3}$, respectively. In general, FA-C particles are found to be coarser than FA-F particles [3] [7]. The particle size distribution of FA-F particles were found to be in the range of 0.1 to $150 \mu \mathrm{m}$, while those of FA-C particles were in the range of 1 to $180 \mu \mathrm{m}$. The SEM micrographs of the FA particles shown in Figure 1 confirm wider particle size distribution in FA-C in comparison to FA-F. The elemental and chemical compositions of the two types of FA are characterized by SEM-EDX and XRD; respectively, as shown in Table 2. It can be noticed that the calcium content in FA-C is twice as that in FA-F; while the iron content in FA-F is almost four times higher than the amount in FA-C. XRD spectrums (Figure 2) of both the types of fly ash shows that periclase (MgO) exists only in FA-C. It also shows that lime and quartz are higher in FA-C compared to FA-F, while FA-F has higher amounts of mullite and hematite compared to FA-C.

\subsection{PVC-FA Foam Composite Characterization}

\subsubsection{Physical Properties}

The theoretical and measured densities of the extruded PVC foam samples are listed in Table 3. The measured 
Table 2. Elemental composition of FA-F and FA-C characterized by SEM/EDX.

\begin{tabular}{ccc}
\hline Component & Class F (Wt \%) & Class C (Wt\%) \\
\hline Silicon & 23.95 & 26.39 \\
Oxygen & 17.28 & 13.75 \\
Aluminum & 14.25 & 15 \\
Iron & 22.65 & 5.77 \\
Calcium & 13.22 & 26.78 \\
Potassium & 1.58 & 1.77 \\
Sodium & 1.05 & 1.27 \\
Titanium & 1.04 & 0.71 \\
Sulfur & 3.11 & 1.15 \\
Magnesium & 1.08 & 2.10 \\
Carbon & 0.53 & 0.57 \\
\hline
\end{tabular}

Table 3. Density of extruded PVC-FA foam composites.

\begin{tabular}{ccc}
\hline Sample & Measured Density $\left(\mathrm{g} / \mathrm{cm}^{3}\right)$ & Theoretical Density $\left(\mathrm{g} / \mathrm{cm}^{3}\right)$ \\
\hline FA0 & 0.39 & 1.39 \\
FA-F6 & 0.44 & 1.43 \\
FA-C6 & 0.43 & 1.45 \\
FA-F40 & 0.89 & 1.66 \\
FA-C40 & 0.69 & 1.68 \\
\hline
\end{tabular}
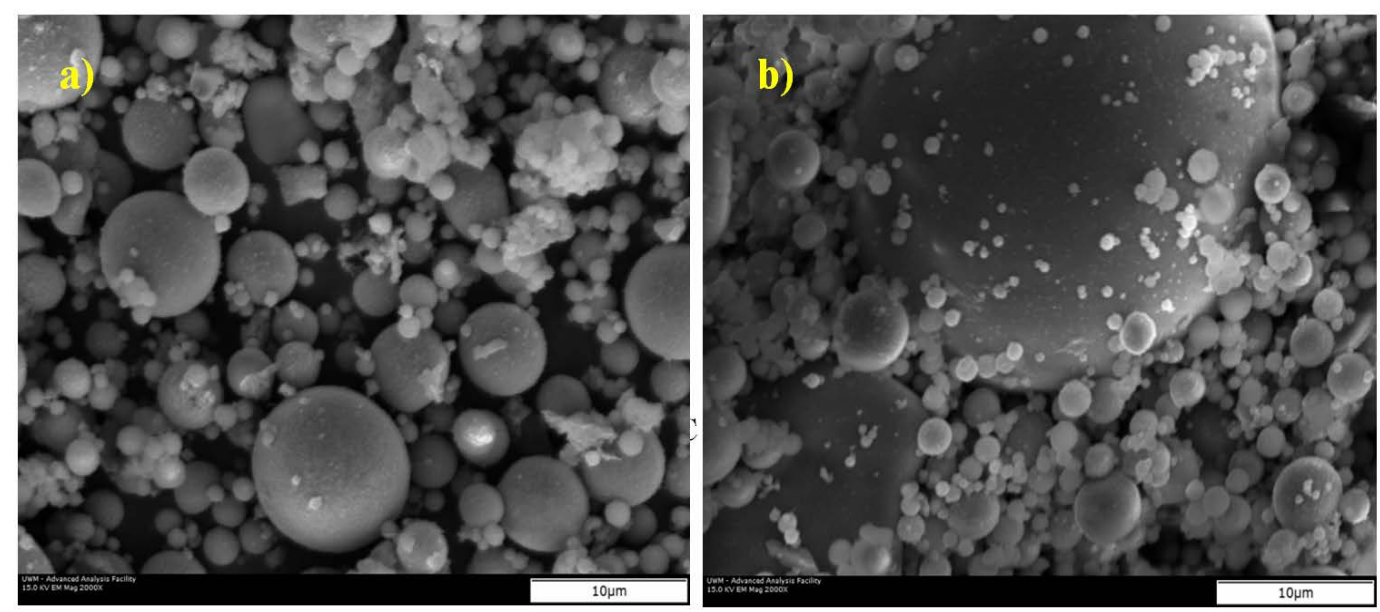

Figure 1. SEM micrograph of a) FA-F and b) FA-C showing the wide range of spherical particles.

density was obtained by weighing a fixed volume of the extruded foam material; whereas the theoretical density was calculated using the rule of mixtures for the unfoamed material. Based on the measured density of the composites, FA-C reinforced composites were lighter compared to the composites reinforced with FA-F. This can be attributed to the different elemental and chemical compositions of class C and F FA. Based on SEM-EDX and XRD results, FA-C has more calcium content than class F, while FA-F has more iron compared to class C.

In addition, calcium is lighter and more reactive than iron, which could be the main reason for the observed 


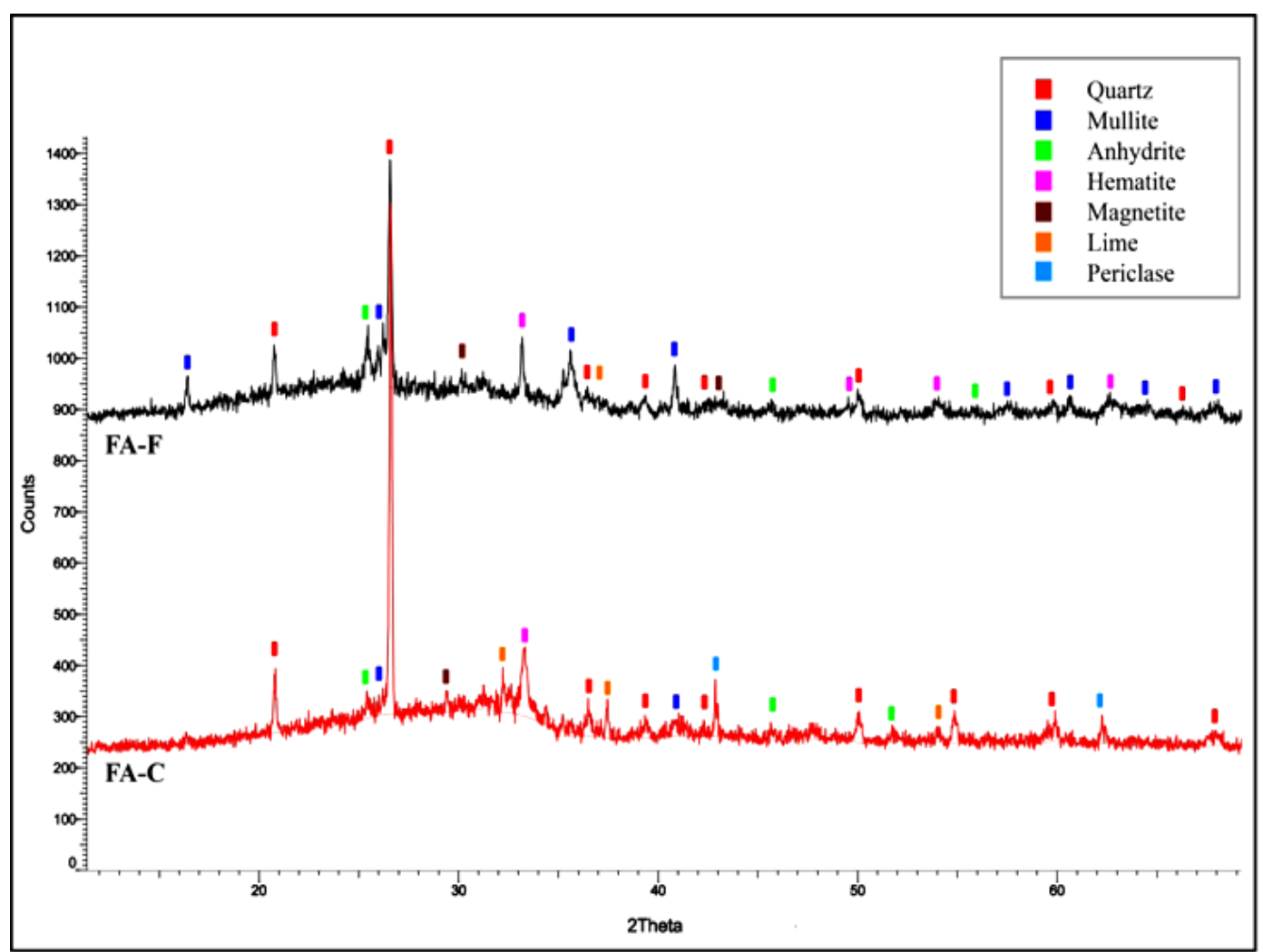

Figure 2. XRD spectrum of FA-C and FA-F.

density values in composites reinforced with FA-C.

\subsubsection{Mechanical Properties}

As seen in Table 4, the incorporation of 6 phr FA to PVC foam improves the tensile strength of the composites and this increment is more significant in FA-C6. The slower rate of increase in tensile strength compared of the FA40 composites compared to the rigid PVC foam without any FA may be due to higher probability of agglomeration of filler particles in the matrix at higher filler loading. The maximum tensile strength is observed in FA-C6 and may be attributed to good filler-matrix interfacial adhesion [27]. This can also be attributed to the chemical composition of FA-C. The presence of periclase in FA-C along with higher lime and quartz contents compared to class $\mathrm{F}$ may have led to better interaction between the filler and the matrix.

The effect of FA on the tensile modulus of composites is shown in Table 4. The addition of FA to PVC foam increases its tensile modulus. At the same amount of FA (6 or $40 \mathrm{phr}$ ), composite samples containing FA-C show a higher modulus value. FA-C filled composites have lower elongation at UTS values in comparison to class F composites; this may be due to increased rigidity imparted by the mineralogical phases in FA-C which may lower the polymer mobility as a result of strong interaction between FA-C filler and polymer matrix [1].

The addition of $6 \mathrm{phr}$ of FA-C to the PVC foam matrix resulted in a 5.74\% decrease in flexural strength, while incorporating the same amount of FA-Cled to a 95\% increase in the flexural strength. It can also be observed that FA-C40 yields a 46\% higher flexural strength than FA-F40. This behavior confirms that FA-C can interact better with PVC matrix than class F. It is also worth noting that FA-C6 shows higher flexural strength than FA-C40, which may be attributed to poor filler dispersion, higher stress concentration, and higher defect and agglomeration probability in highly loaded composites [6]. At the same FA loading, either 6 or $40 \mathrm{phr}$, class C filled samples exhibit higher flexural strength due to higher calcium content in class $C$, which improves the reactivity of FA with the polymer matrix.

The flexural modulus was found to improve significantly upon adding 6 phr FA into the PVC foam matrix and this improvement is significant in FA-C6 than FA-F6. The increase in flexural modulus of FA filled composites is a result of the inherent rigidity of the FA filler, which is more significant in highly loaded composites. 
Table 4. Mechanical properties of PVC-FA foam composites.

\begin{tabular}{ccccccccc}
\hline Sample & $\begin{array}{c}\text { Tensile } \\
\text { Strength (MPa) }\end{array}$ & $\begin{array}{c}\text { Tensile } \\
\text { Modulus } \\
(\mathrm{MPa})\end{array}$ & $\begin{array}{c}\text { Elongation } \\
\text { at UTS } \\
(\mathrm{mm})\end{array}$ & $\begin{array}{c}\text { Flexural } \\
\text { Strength } \\
(\mathrm{MPa})\end{array}$ & $\begin{array}{c}\text { Flexural } \\
\text { Modulus } \\
(\mathrm{MPa})\end{array}$ & $\begin{array}{c}\text { Impact } \\
\text { Energy } \\
(\mathrm{J})\end{array}$ & $\begin{array}{c}\text { Impact } \\
\text { strength } \\
\left(\mathrm{KJ} / \mathrm{m}^{2}\right)\end{array}$ & $\begin{array}{c}\text { Hardness } \\
(\text { Shore D) }\end{array}$ \\
\hline FA0 & 9.06 & 213.35 & 134.30 & 18.54 & 353.6 & 0.21 & 2.88 & 90 \\
FA-F6 & 9.11 & 219.72 & 32.78 & 17.47 & 576.15 & 0.15 & 2.07 & 91 \\
FA-C6 & 12.05 & 257.52 & 29.35 & 35.83 & 652.52 & 0.19 & 2.71 & 91 \\
FA-F40 & 11.52 & 365.75 & 19.96 & 21.18 & 1180.5 & 0.11 & 1.57 & 94 \\
FA-C40 & 10.26 & 483.14 & 15.57 & 30.94 & 1163.3 & 0.10 & 1.52 & 94 \\
\hline
\end{tabular}

Highly loaded composites FA-F40 and FA-C40 have almost the same flexural modulus.

The impact strength and impact energy decrease by incorporating FA in PVC matrix. The samples containing 6 phr of FA-C show higher impact strength compared to other samples, which represent more efficient load transfer. Moreover, this observation is consistent with the flexural strength and the elongation at UTS results indicating an increase in rigidity of the composites upon reinforcing them with either type of FA.

The hardness of PVC foam composites was found to increase as the amount of FA increased. The increase can be which validate the tensile modulus results. However, there was no significant difference between the hardness of the composites containing either FA-C or FA-F.

\subsubsection{Thermal Properties}

The decomposition of PVC yields two recognized steps, separation of chlorine at Primary Degradation Temperature (PDT) and subsequently cracking of the hydrocarbon backbone at the Secondary Degradation Temperature (SDT) [28]. The results from TGA analysis of the PVC/FA foam composites are presented in Figure 3 and the decomposition temperatures are summarized in Table 5. The samples without any FA; i.e. FA0, shows PDT and SDT at $277^{\circ} \mathrm{C}$ and $429^{\circ} \mathrm{C}$, respectively. The PDT is found to decrease slightly with the addition of FA particles; e.g. PDT of FA-C6 decreases by $2^{\circ} \mathrm{C}$ compared to FA0.

SDT of FA filled composites is found to improve significantly which means that it takes more energy to break the hydrocarbon backbone indicating some bonding between the filler and the matrix. The maximum SDT increment is approximately $16^{\circ} \mathrm{C}$ in FA-C6 compared to FA0, which is due to better bonding between FA-Cand PVC matrix. Comparison between samples with the same FA loadings shows that at low filler loading, class C loaded samples have higher SDT compared to class F. However, a change in this pattern can be seen in samples containing higher amounts of fly ash (40 phr) as both types of composites exhibit almost the same SDT.

The residual weight of the composites determined by TGA analysis contains the undecomposed inorganic fillers and ash [29]. Residual weight at $800^{\circ} \mathrm{C}$ was found to be $9.31 \%$ in FA0 which does not contain any FA. The residual weight in both FA-F6 and FA-C6 samples was around 19\% and around 40\% in both FA-F40 and FA-C40 samples.

DSC was used to determine the effect of FA-C and FA-F on the glass transition temperature $\left(T_{g}\right)$ of the composites. The degree of gelation, initial $\left(\mathrm{Tg}_{\mathrm{i}}\right)$, middle $\left(\mathrm{Tg}_{\mathrm{m}}\right)$, and final $\mathrm{T}_{\mathrm{g}}\left(\mathrm{Tg}_{\mathrm{f}}\right)$ values are reported in Table 6 . The results suggest that incorporating FA as filler does not impact the Tg of the PVC foam composites significantly. This behavior is similar to the results observed in PVC/cumbaru filler and PVC/Carbon fiber composite systems reported by Iulianell et al. [30] and Ráthy et al. [31], respectively.

The percentage of gelation is estimated according to melting enthalpy (J/g) obtained from the primary and secondary endotherms of DSC curves [32]-[35]. The addition of FA causes a decrease in the degree of gelation. Considering the composites with $6 \mathrm{phr} F A$, it can be seen that class $C$ filled samples show higher degree of gelation, which shows better fusion of particles with the matrix. This result can be also seen in samples with 40phr FA-C composites. This observation may be the result of better interfacial interaction between FA-C and PVC matrix at lower loading which can accelerate the gelled network formation.

The viscoelastic properties of composites determined by DMA are reported in Figure 4(a) and Figure 4(b) in terms of variations of the storage modulus $\left(E^{\prime}\right)$, which represents the elastic nature, and loss modulus $\left(E^{\prime \prime}\right)$ which represents the viscous nature, as a function of temperature. The magnitude of $E^{\prime}$ seems to increase significantly 
Table 5. Thermogravimetric Analysis of foam composites.

\begin{tabular}{cccc}
\hline Sample & $\mathrm{PDT}^{1}\left({ }^{\circ} \mathrm{C}\right)$ & $\mathrm{SDT}^{2}\left({ }^{\circ} \mathrm{C}\right)$ & $\begin{array}{c}\text { \%Residual weight } \\
\text { at } 800^{\circ} \mathrm{C}\end{array}$ \\
\hline FA0 & 277.02 & 428.76 & 9.31 \\
FA-F6 & 270.02 & 444.73 & 19.48 \\
FA-C6 & 275.05 & 446.68 & 18.76 \\
FA-F40 & 265.23 & 438.25 & 37.13 \\
FA-C40 & 271.21 & 438.18 & 40.72 \\
\hline
\end{tabular}

${ }^{1}$ PDT-Primary Decomposition Temperature; ${ }^{2}$ SDT-Secondary Decomposition Temperature.

Table 6. $T_{g}$ values and percentage of gelation obtained from DSC of PVC foam composites.

\begin{tabular}{|c|c|c|c|c|}
\hline Sample & $\operatorname{Tg}_{\mathrm{i}}$ & $\operatorname{Tg}_{m}$ & $\mathrm{Tg}_{\mathrm{f}}$ & $\%$ Gelation \\
\hline FA0 & 82.28 & 82.28 & 86.49 & 85.63 \\
\hline FA-F6 & 82.63 & 82.63 & 85.83 & 80.54 \\
\hline FA-C6 & 79.19 & 82.63 & 87.83 & 88.27 \\
\hline FA-F40 & 82.36 & 82.36 & 86.84 & 62.94 \\
\hline FA-C40 & 80.04 & 84.00 & 86.60 & 79.50 \\
\hline
\end{tabular}

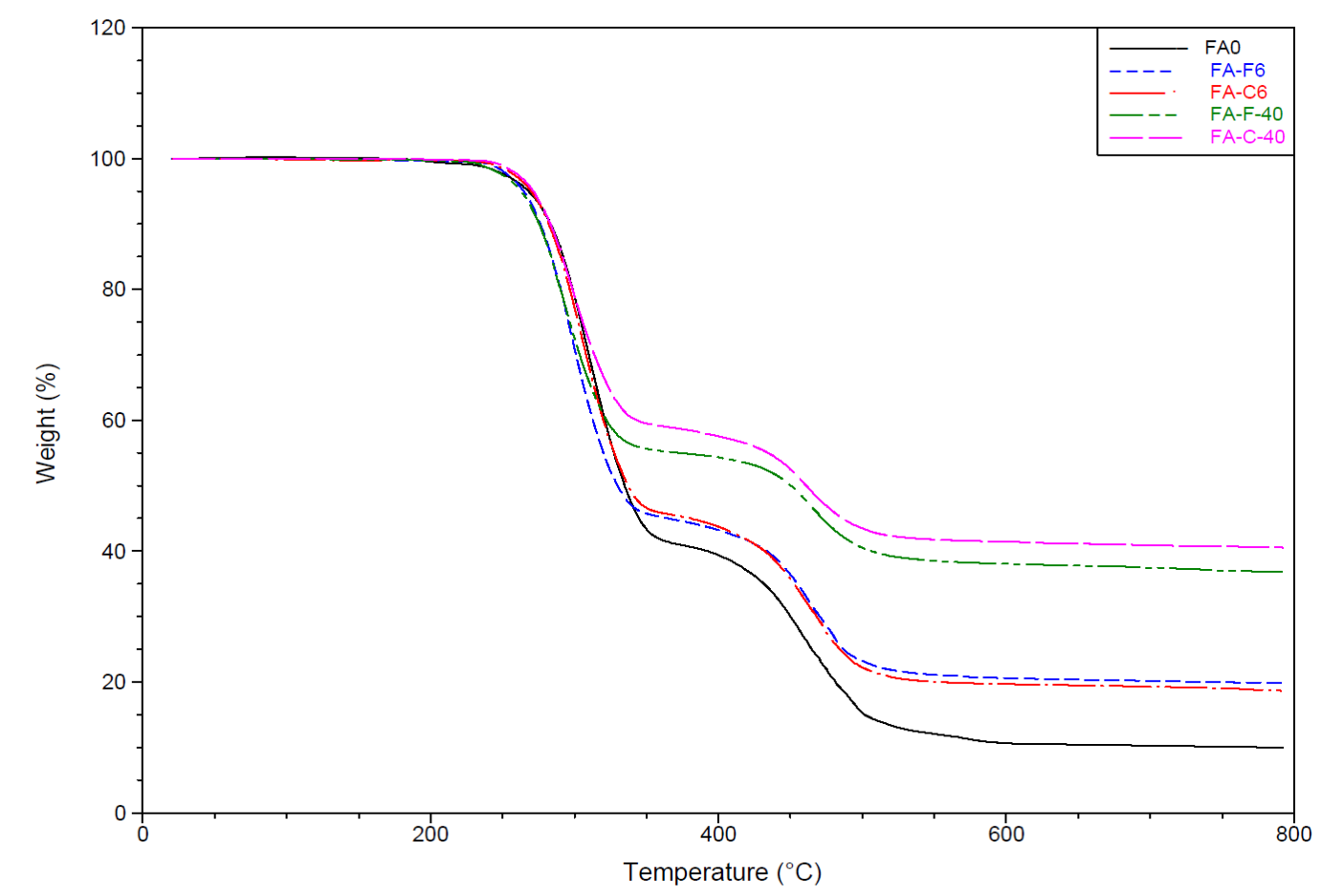

Figure 3. TGA curves of PVC/FA foam composites.

with the incorporation of FA filler. This increase indicates an improvement of the stiffness with further loading of FA, which is in accordance with the expectations of the common behavior of rigid spherical particle filled composites [4]. The increase seems to be more remarkable in class $C$ filled composites compared to the ones containing FA-F. The storage modulus of FA-C6 at $50^{\circ} \mathrm{C}$ is approximately $475 \mathrm{MPa}$ which is $6 \%$ higher than FA-F6 and 58\% higher than FA0. Whereas, storage modulus of 40 phr FA loaded samples are about the same. 


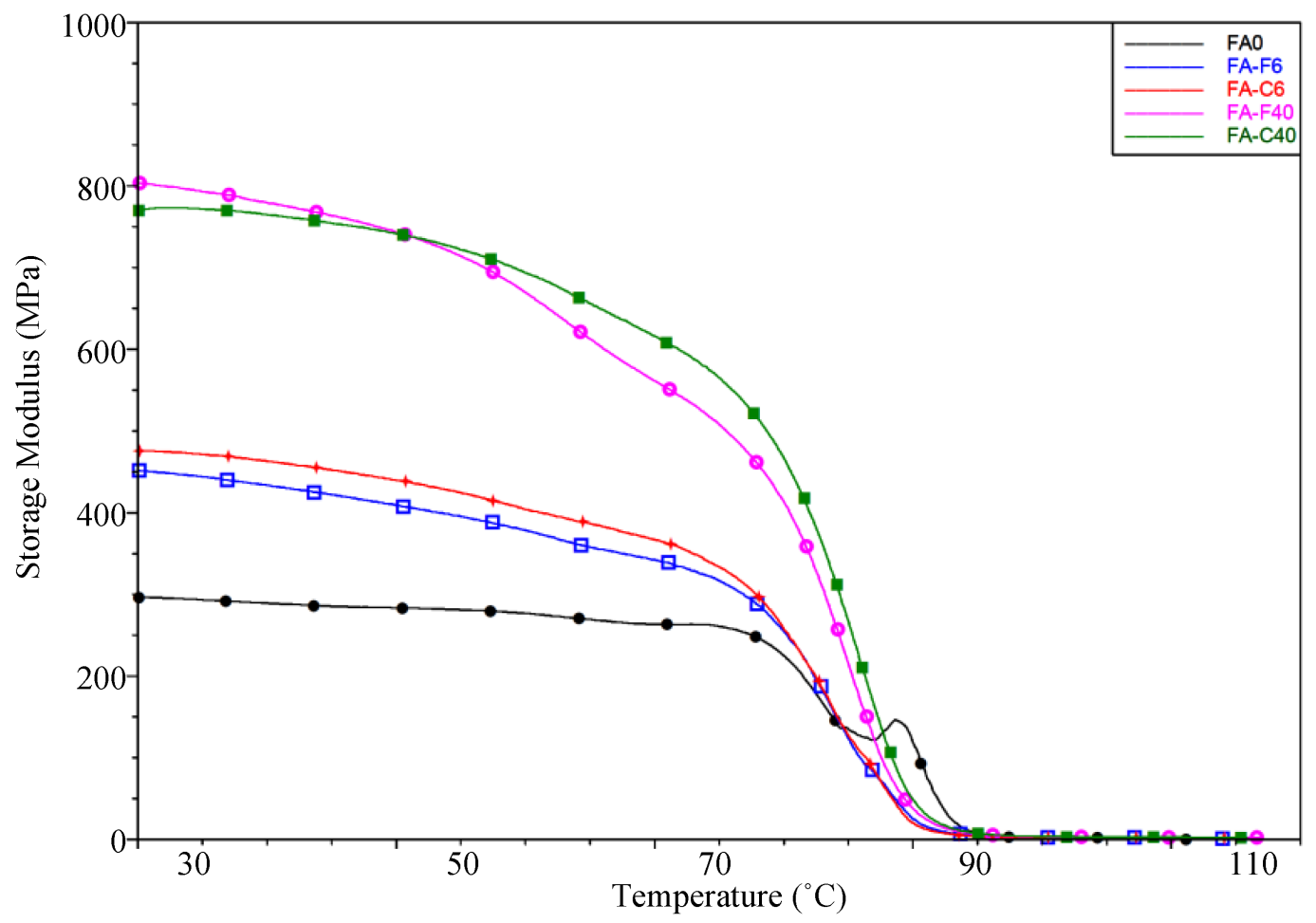

(a)

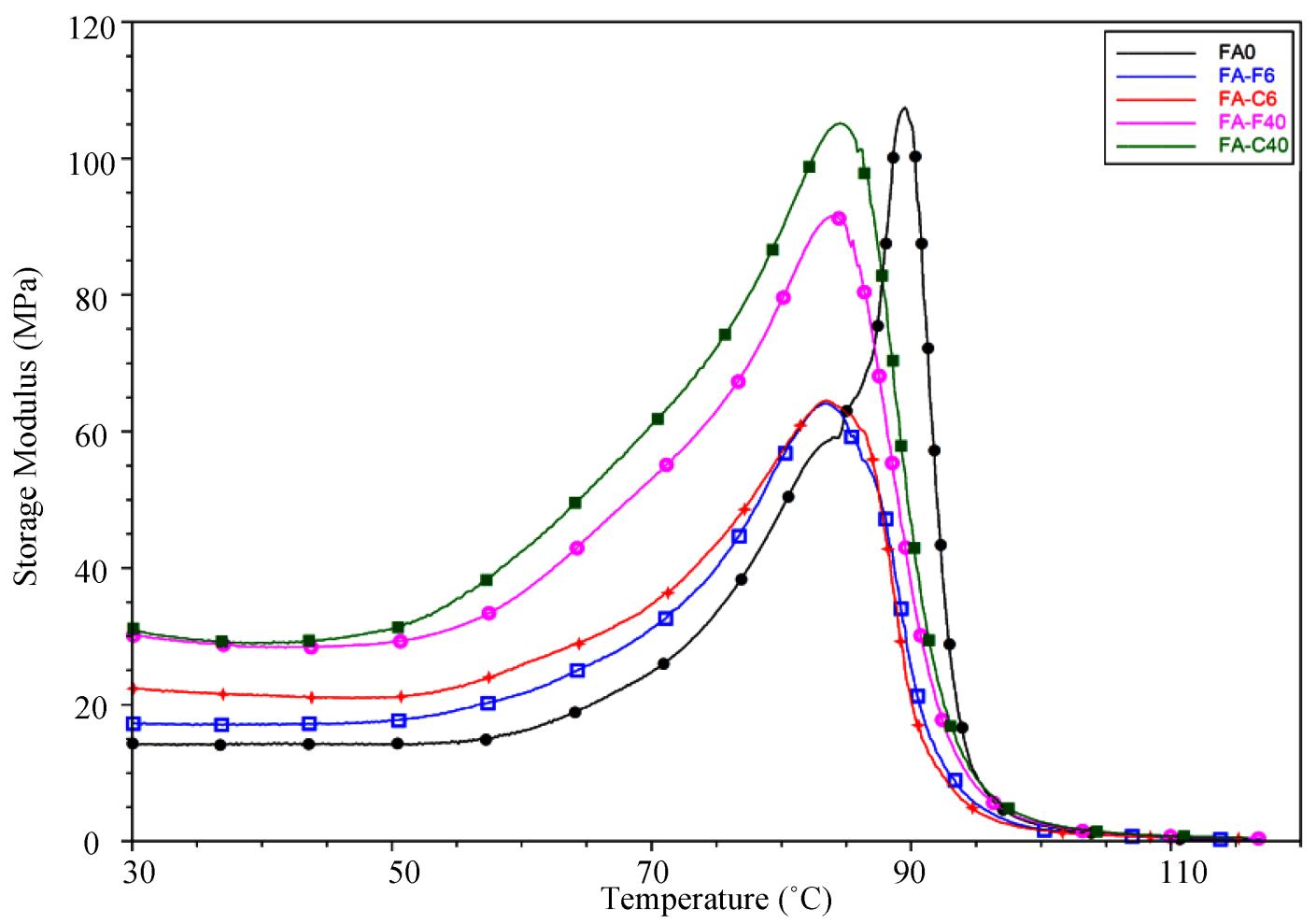

(b)

Figure 4. Dynamic mechanical behavior of PVC foam composites (a) storage modulus $\left(E^{\prime}\right)$ and (b) loss modulus $\left(E^{\prime \prime}\right)$. 
At higher temperatures, such as $70^{\circ} \mathrm{C}$, FA-C40 shows higher storage modulus. This may be due to the fact that it is well below the glass transition temperature of the PVC foam composites and the storage modulus is a measure of the stored energy of the material rendering it more elastic. This behavior is in line to the higher tensile modulus values of FA-C composites.

The peak intensity of loss modulus is found to decrease with the addition of $6 \mathrm{phr} F A$, irrespective of the type of fly ash (FA-F or FA-C) used in the PVC foam. However, in highly loaded composites; i.e., FA-F40 and FA-C40, the loss modulus was found to improve. This phenomenon may be attributed to the enhancement in the energy dissipation ability as a result of the presence of spherical filler in the composites and also the increase in the polymer-filler and filler-filler slippages at $T_{g}[8]$.

\subsubsection{Microstructural Properties}

Microstructure analysis was conducted on PVC foam composites to evaluate the interfacial interaction between FA particles and foam matrix, and also to determine the state of dispersion and distribution of FA particles in the composites. As seen in Figures 5(a)-(e), the amount of visible FA particles was high in the composites containing higher amounts ( $40 \mathrm{phr}$ ) of FA in comparison to the ones containing lower amounts (6 phr) of FA. A good distribution can be seen in the composites at lower loadings [27]. However, in FA-F40 and FA-C40, particle agglomeration can be seen in some parts of the SEM image (Figure 5(b) and Figure 5(d)).

The presence of tightly embedded and mechanically interlocked FA particles within the PVC matrix in all composites indicates strong interaction between filler and matrix and also good dispersion of filler particles. In composites FA-F40 and FA-C40, filler debonding areas on the fractured surface can be noticed. This may be due to high filler loading and dewetting of FA surfaces with PVC matrix.

\section{Conclusions}

PVC foam-FA composites containing two different classes of FA, C and F, were successfully extruded in a simple rectangular profile. It was found that FA-C interacts better with PVC matrix and improves the mechanical

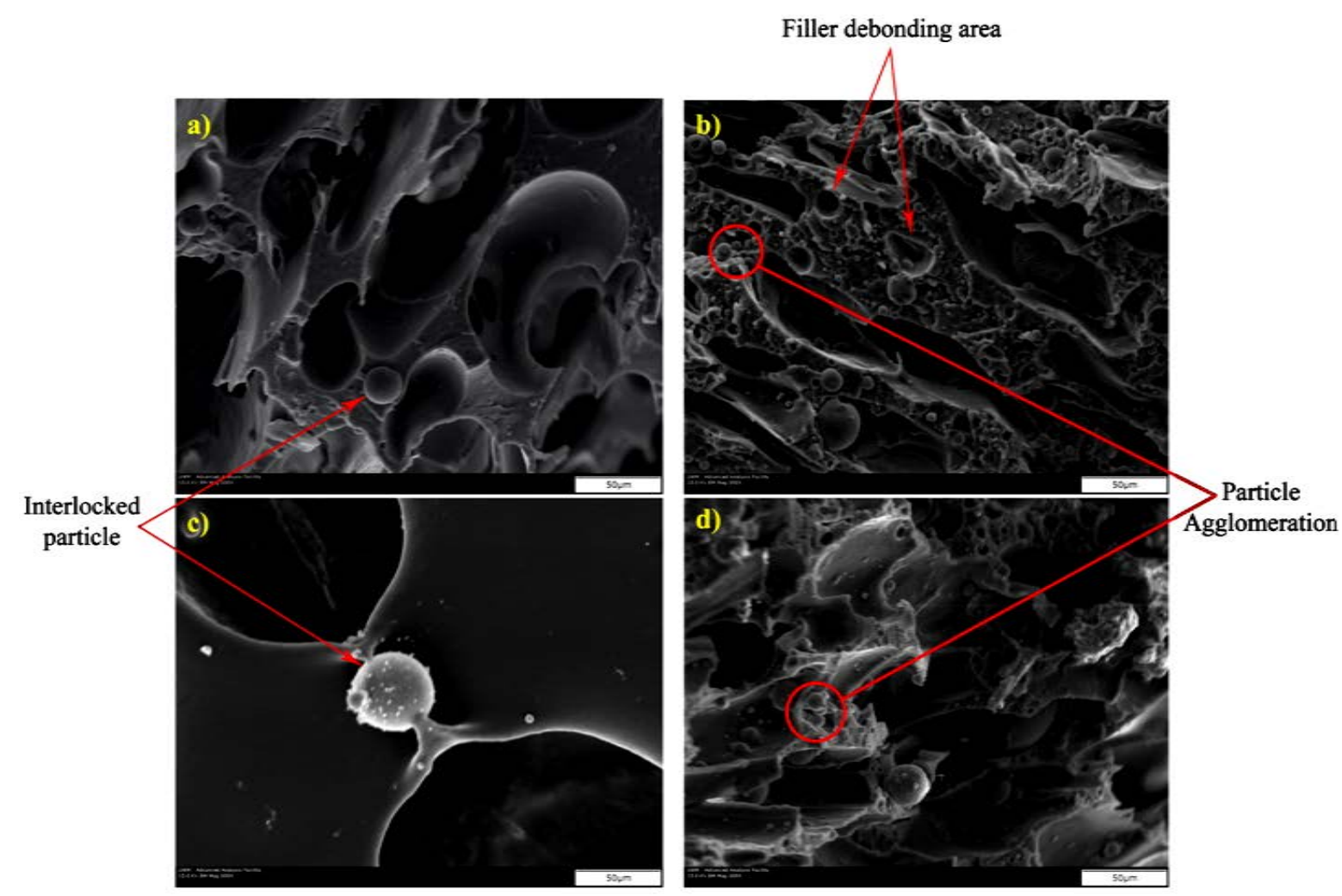

Figure 5. SEM micrograph of the PVC foam composites, a) FA-F6, b) FA-C6, c) FA-F40, and d) FA-C40. 
properties of the PVC foam composites significantly when compared to FA-F. The density of the composites containing FA-C was lower than FA-F due to more efficient foaming as a result of better dispersion, distribution and interaction with PVC matrix. Meanwhile, the hardness of the composites remained the same regardless of the type of FA. Both the tensile strength and modulus were higher in the composites containing FA-C compared to class F; which indicates better interfacial interaction between the filler and matrix. Whereas, elongation at UTS of class $\mathrm{C}$ composites was lower than class $\mathrm{F}$ due to increased rigidity which lowers polymer mobility in class $\mathrm{C}$ composites as a result of the strong interaction between the filler and the polymer matrix. Similarly, flexural strength and flexural modulus were higher in the composites containing FA-C, where samples with 6 phr FA-C exhibited the maximum flexural strength. Both the impact strength and impact energy decreased as the filler loading increased, with FA-C6 showing the highest impact strength due to better load transfer.

SEM images confirmed good dispersion, distribution, and interaction between FA and PVC matrix, especially in the case of FA-C6. Agglomeration, dewetting, and debonding were observed in highly loaded samples of both FA types. Thermal behavior of PVC/fly ash foam composites, measured with DSC and TGA, showed that the gelation degree of class $C$ filled composites was higher than class $F$ at 6 phr loading level. Primary and secondary decomposition temperatures showed the highest improvement in FA-C6. Dynamic mechanical properties confirmed higher stiffness in composites containing FA-C and also the presence of good interfacial adhesion between filler and matrix.

\section{References}

[1] Sreekanth, M.S. and Bambole, V.A. (2009) Effect of Particle Size and Concentration of Flyash on Properties of Polyester Thermoplastic Elastomer Composites. Journal of Minerals \& Materials Characterization \& Engineering, 8, 237-248.

[2] Matsunaga, T., Kim, J.K., Hardcastle, S. and Rohatgi, P.K. (2002) Crystalinity and Selected Properties of Fly Ash Particles. Materials Science and Engineering, A325, 333-343. http://dx.doi.org/10.1016/S0921-5093(01)01466-6

[3] White, S.C. and Case, E.D. (1990) Characterization of Fly Ash from Coal-Fired Power Plants. Journal of Materials Science, 25, 5215-5219. http://dx.doi.org/10.1007/BF00580153

[4] Gamage, N., Liyanage, K., Fragomeni, S. and Setunge, S. (in press) Overview of Different Types of Fly Ash and Their Use as a Building and Construction Material.

[5] Khairul, N.I., Kamarudin, H. and Mohd, S.I. (2007) Physical, Chemical, and Mineralogical Properties of Fly Ash. Journal of Nuclear Related Technology, 4, 47-51.

[6] Labella, M., Zeltmann, S.E., Shunmugasamy, V.C., Gupta, N. and Rohatgi, P.K. (2014) Mechanical and Thermal Properties of Fly Ash/Vinyl Ester Syntactic Foams. Fuel, 121, 240-249. http://dx.doi.org/10.1016/j.fuel.2013.12.038

[7] Senapati, A.K., Bhatta, A., Mohanty, S., Mishra, P.C. and Routra, B.C. (2014) An Extensive Literature Review on the Usage of Fly Ash as a Reinforcing Agent for Different Matrices. International Journal of Innovation Science \& Modern Engineering, 2, 4-9.

[8] Qiao, J., Amirkhizi, A.V., Schaaf, K. and Nemat-Nasser, S. (2011) Dynamic Mechanical Analysis of Fly Ash Filled Polyurea Elastomer. Journal of Engineering Materials \& Technology, 133, 110161-110167. http://dx.doi.org/10.1115/1.4002650

[9] Anandhan, S., Sundar, S.M., Senthil, T., Mahendran, A.R. and Shibulal, G.S. (2012) Extruded Poly(ethylene-co-octene)/ Fly Ash Composites-Value Added Products from an Environmental Pollutant. Journal of Polymer Research, 19, 98409851. http://dx.doi.org/10.1007/s10965-012-9840-6

[10] Deepthi, M.V., Sharma, M., Sailaja, R.R.N., Anantha, P., Sampathkumaran, P. and Seetharamu, S. (2010) Mechanical and Thermal Characteristics of High Density Polyethylene-Fly ash Cenospheres Composites. Materials \& Design, 31, 2051-2060. http://dx.doi.org/10.1016/j.matdes.2009.10.014

[11] Doddamani, M.R. and Kulkarni, S.M. (2011) Dynamic Response of Fly Ash Reinforced Functionally Graded Rubber Composite Sandwiches-A Taguchi Approach. International Journal of Engineering, Science \& Technology, 3, 166182. http://dx.doi.org/10.4314/ijest.v3i1.67644

[12] Nath, D.C.D., Bandyopadhyay, S., Yu, A., Zeng, Q., Das, T., Blackburn, D. and White, C. (2009) Structure-Property Interface Correlation of Fly Ash-Isotactic Polypropylene Composites. Journal of Materials Science, 44, 6078-6089. http://dx.doi.org/10.1007/s10853-009-3839-3

[13] Nath, D.C.D., Bandyopadhyay, S., Yu, A., Blackburn, D. and White, C. (2010) Novel Observations on Kinetics of Nonisothermal Crystallization in Fly Ash Filled Isotactic-Polypropylene Composites. Journal of Applied Polymer Science, 115, 1510-1517. http://dx.doi.org/10.1002/app.31186 
[14] Nath, D.C.D., Bandyopadhyay, S., Yu, A., Blackburn, D., White, C. and Varughese, S. (2010) Isothermal Crystallization Kinetics of Fly Ash Filled Iso-Polypropylene Composite- and a New Physical Approach. Journal of Thermal Analysis and Calorimetry, 99, 423-429. http://dx.doi.org/10.1007/s10973-009-0408-6

[15] Nath, D.C.D., Bandyopadhyay, S., Boughton, P., Yu, A., Blackburn, D. and White, C. (2010) High-Strength Biodegradable Poly(vinyl Alcohol)/Fly Ash Composite Films. Journal of Applied Polymer Science, 117, 114-121.

[16] Nath, D.C.D., Bandyopadhyay, S., Yu, A., Blackburn, D. and White, C. (2010) High Strength Bio-Composite Films of Poly(vinyl Alcohol) Reinforced with Chemically Modified-Fly Ash. Journal of Materials Science, 45, 1354-1360. http://dx.doi.org/10.1007/s10853-009-4091-6

[17] Vijaykumar, H.K., Prashanth, M., Saheb, S. and Nayak, V. (2014) Experimental Investigation of the Tensile Strength and Compressive Strength of Fly Ash Core Sandwiched Composite Material. Journal of International Organization Scientific Research, 4, 1-10.

[18] Guhanathan, S. and Sarojadevi, M. (2004) Studies on Interface in Polyester/Fly-Ash Particulate Composites. Composite Interface, 11, 43-66. http://dx.doi.org/10.1163/156855404322681046

[19] Bishoyee, N., Dash, A., Mishra, A., Patra, S. and Mahapatra, S.S. (2010) A Grey-Based Taguchi Approach for Characterization of Erosive Wear Phenomenon of Glass-Polyester Fly Ash Filled Composites. Journal of Polymer Environment, 18, 177-187. http://dx.doi.org/10.1007/s10924-010-0196-X

[20] Usta, N. (2012) Investigation of Fire Behavior of Rigid Polyurethane Foams Containing Fly Ash and Intumescent Flame Retardant by Using a Cone Calorimeter. Journal of Applied Polymer Science, 124, 3372-3382. http://dx.doi.org/10.1002/app.35352

[21] Chow, J.D., Chai, W.L., Yeh, C.M. and Chuang, F.S. (2008) Recycling and Application Characteristics of Fly Ash from Municipal Solid Waste Incinerator Blended with Polyurethane Foam. Environmental Engineering Science, 25, 461-471. http://dx.doi.org/10.1089/ees.2006.0037

[22] Gupta, N., Woldesenbet, E. and Mensah, P. (2004) Compression Properties of Syntactic Foams: Effect of Cenosphere Radius Ratio and Specimen Aspect Ratio. Composites Part A: Applied Science and Manufacturing, 35, 103-111. http://dx.doi.org/10.1016/j.compositesa.2003.08.001

[23] Rabinovich, E.B., Isner, J.D., Sidor, J.A. and Wiedl, D.J. (1997) Effect of Extrusion Conditions on Rigid PVC Foam. Journal of Vinyl \& Additive Technology, 3, 210-215. http://dx.doi.org/10.1002/vnl.10193

[24] Thomas, N.L. (2004) Rigid PVC Foam, Formulating for Sustainability, Blowing Agent and Foaming Process.

[25] Eaves, D. (2004) Handbook of Polymer Foams.

[26] Thomas, N.L. (2004) Proceedings of 6th International Conference of Blowing Agent and Foaming Process. 10-11 May 2004, Hamburg.

[27] Das, A. and Satapathy, B.K. (2011) Structural, Thermal, Mechanical and Dynamic Mechanical Properties of Cenosphere Filled Polypropylene Composites. Materials \& Design, 32, 1477-1484. http://dx.doi.org/10.1016/j.matdes.2010.08.041

[28] Lu, H., Purushothama, S., Hyatt, J., Pan, W.P., Riley, J.T., Lloyd, W.G., et al. (1996) Co-Firing High-Sulfur with Refuse-Derived Fuel. Thermochimica Acta, 284, 161-177. http://dx.doi.org/10.1016/0040-6031(96)02864-X

[29] Lodi, P.C. and Souza, B.B.D. (2012) Thermo-Gravimetric Analysis (TGA) after Different Exposures of High Density Polyethylene (HDPE) and Poly Vinyl Chloride (PVC) Geomembranes. Electronic Journal of Geotechnical Engineering, 17, 3339-3349.

[30] Iulianelli, C.G.V., Maciel, P.M.C. and Tavares, M.I.B. (2011) Preparation and Characterization of PVC/Natural Filler Composites. Macromolecular Symposia, 299, 227-233. http://dx.doi.org/10.1002/masy.200900104

[31] Ráthy, I., Kuki, A., Borda, J., Deák, G., Zsuga, M., Marossy, K., et al. (2012) Preparation and Characterization of Poly(vinyl Chloride)-Continuous Carbon Fiber Composites. Journal of Applied Polymer Science, 124, 190-194. http://dx.doi.org/10.1002/app.33617

[32] Fillot, L.A., Hajji, P. and Gauthier, C. (2006) U-PVC Gelation Level Assessment, Part 2: Optimization of the Differential Scanning Calorimetry Technique. Journal of Vinyl \& Additive Technology, 10, 108-114. http://dx.doi.org/10.1002/vnl.20078

[33] Cruz, J. and Gramann, P. (2009) Determining the Quality of a Failed PVC Pipe. Society of Plastic Engineers, 10, 1-3.

[34] Tomaszewska, J., Sterzynski, T. and Piszczek, K. (2004) Rigid Poly(vinyl Chloride) (PVC) Gelation in the Brabender Measuring Mixer. I. Equilibrium State Between Sliding, Breaking, and Gelation of PVC. Journal of Applied Polymer Science, 93, 966-971. http://dx.doi.org/10.1002/app.20519

[35] Piszczek, K., Tomaszewska, J. and Sterzynski, T. (2010) The Influence of Temperature of Poly(vinyl Chloride) Melt on the Equilibrium State of Gelation Process. Polymery, 55, 678-680. 
Scientific Research Publishing (SCIRP) is one of the largest Open Access journal publishers. It is currently publishing more than 200 open access, online, peer-reviewed journals covering a wide range of academic disciplines. SCIRP serves the worldwide academic communities and contributes to the progress and application of science with its publication.

Other selected journals from SCIRP are listed as below. Submit your manuscript to us via either submit@scirp.org or Online Submission Portal.
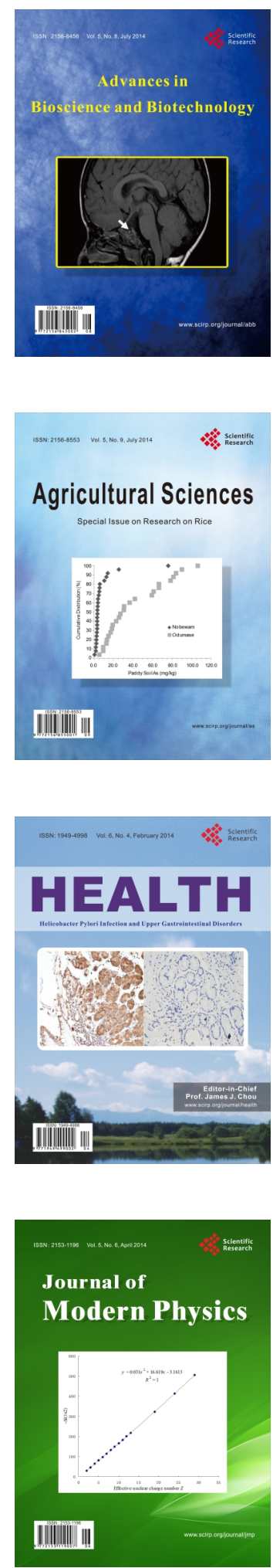
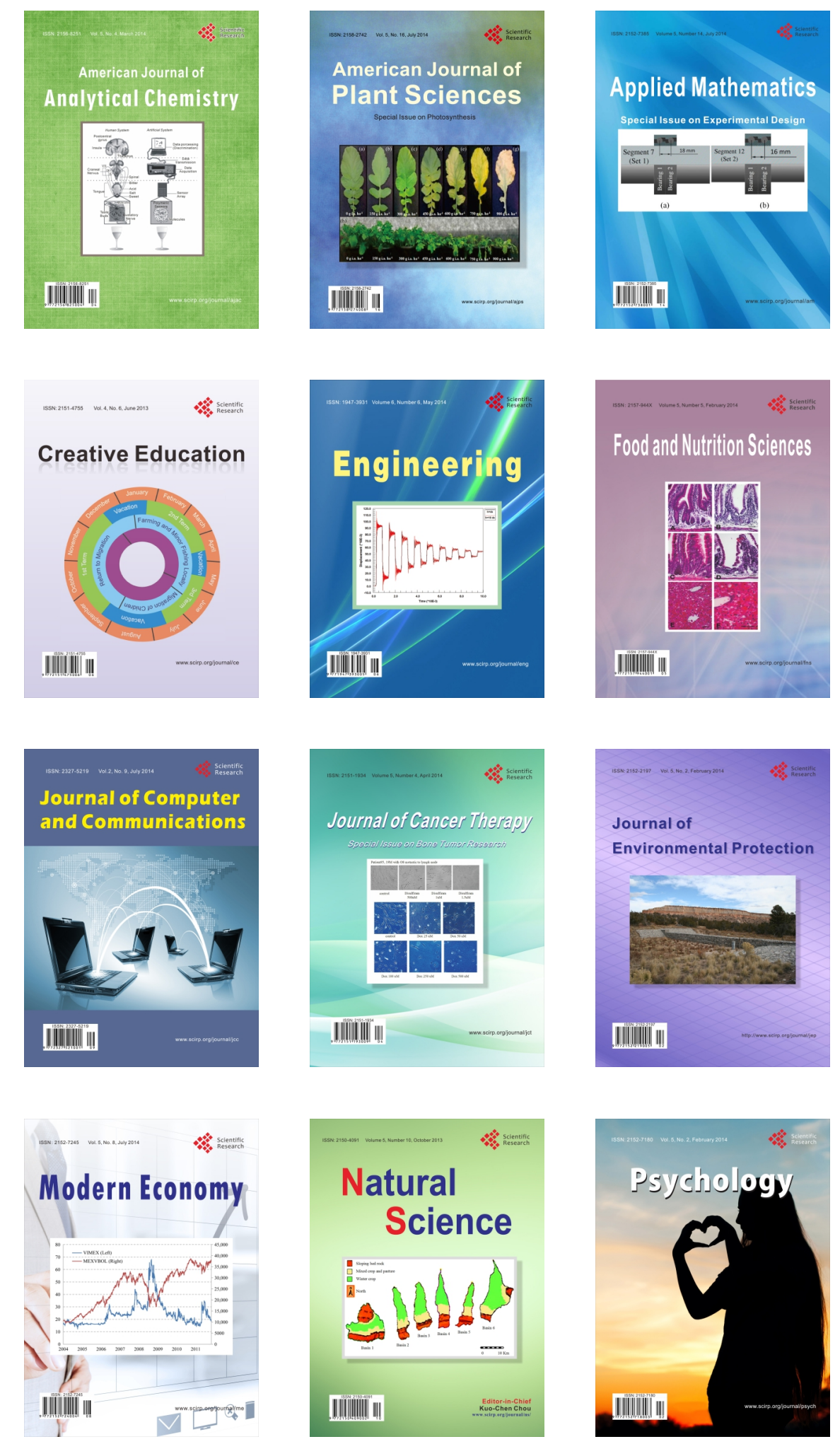